\title{
ANÁLISE DE JOGO NO FUTSAL: AÇÕES DEFENSIVAS E O CONTRA-ATAQUE
}

\section{Wilton Carlos de Santana}

Universidade Estadual de Londrina, Londrina, Paraná, Brasil

\section{Loani Landin Istchuck}

Universidade Estadual de Londrina, Londrina, Paraná, Brasil

\section{Felipe Rafael Andreoli Conceição}

Universidade Estadual de Londrina , Londrina, Paraná, Brasil

\section{Caroline Santos Guilardi}

Universidade Estadual de Londrina, Londrina, Paraná, Brasil

\section{Ênio Ricardo Vaz Ronque}

Universidade Estadual de Londrina , Londrina, Paraná, Brasil

\section{Resumo}

Este artigo objetiva descrever e analisar a frequência e a tipologia das ações defensivas que desencadearam contra-ataques (CA) em jogos de futsal. Levantamos ações empregadas pela linha e pelo goleiro diante do ataque posicional e do CA. Foram analisadas $125(31,75 \pm 2,98)$ ações, retiradas de quatro jogos entre as equipes semifinalistas da VI Copa do Mundo de Futsal. Notou-se que a produção de CA aconteceu, sobretudo, diante do ataque posicional e exigiu da linha interceptar passes, desarmar e bloquear; os goleiros participaram com defesas e rebotes. O presente estudo contribui para a criação de um conjunto de indicadores para o treino defensivo, com o qual os treinadores poderão simular situações contextualizas, a fim de gerar certas regularidades táticas compatíveis com as exigências da modalidade.

Palavras chave: Futsal. Análise. Jogo. Defesa.

\section{Introdução}

A análise de jogo tem se constituído numa valiosa tecnologia de coleta de informação tático-técnica para distintos jogos esportivos coletivos, entre eles, o futsal (AMARAL; GARGANTA, 2005; DUARTE, 2008; 
MARCHI et al, 2010; SANTANA; GARCIA, 2007). Sua utilização revestese de importância à medida em que procura revelar, mediante a análise competitiva, a dinâmica interna desses esportes, lhes identificando peculiaridades e, por conseguinte, apontando indicadores que possam servir aos treinadores quando do planejamento do treino e da regulação da competição (GARGANTA, 2000; 2008).

O contra-ataque (ou ataque rápido) responde por um dos momentos ou fases do jogo de futsal (SAMPEDRO, 1997; SANTANA, 2004), comumente entendido como transição ofensiva, em virtude de a equipe se encontrar em mudança de atitude (BONVICINI, 2004; JABIR, 2004). Tratase de um jogo não sistemático, no qual o tempo é um imperativo (SILVA; CALADO FILHO, 2005). Por isso, o contra-ataque deve ser jogado veloz e verticalmente, a fim de superar os defensores que se empenham para recuperar o equilíbrio posicional e/ou numérico perdido (CHAVES; AMOR, 1998). Quando bem sucedido, o contra-ataque dura desde o momento em que a equipe recupera a bola até a finalização/término da jogada (SANTANA, 2008).

O contra-ataque é a antítese do jogo posicional, que se desenvolve contra uma defesa organizada, isto é, agrupada atrás da linha da bola, no qual o tempo não é um imperativo para o ataque. Neste caso, os atacantes optam por um jogo sistemático (que envolve um desenho tático e um modelo ou padrão de jogo) que facilite a manutenção da posse de bola, e se prestam a criar e ocupar espaços, enfim, a promover a organização das ações ofensivas a fim de envolver a defesa adversária (VELASCO; LORENTE, 2003).

Andrade Junior (2007) reporta que as equipes que contra-atacam com eficácia credenciam-se a marcar gols. Muito provavelmente, a iminência de gols se explicaria em função de o contra-ataque conferir aos atacantes a oportunidade de agir contra uma defesa desequilibrada e/ou inferiorizada, o que, em tese, lhes oportunizaria certa vantagem numérica e/ou posicional.

Esse fato foi corroborado por Fukuda e Santana (2012), e por Santana e Garcia (2007), que verificaram ser o contra-ataque uma das ações que mais geram gols no futsal de alto rendimento; e por Marchi et al., (2010), que diagnosticaram que essa situação tem decidido jogos. No que pesam essas constatações, estes últimos autores verificaram que, ao se considerar a frequência dessas ações nas partidas, o aproveitamento de gols é baixo.

Se por um lado o contra-ataque no futsal de alto rendimento foi estudado quanto à frequência, tipologia e eficácia (FUKUDA; SANTANA, 2012; MARCHI et al., 2010; SANTANA; GARCIA, 2007), por outro, carece de estudos que retratem sua interdependência com aspectos defensivos, como por exemplo, o desarme, a interceptação de passe, o bloqueio e as de-

Pensar a Prática, Goiânia, v. 17, n. 2, p. 431-442, jan./mar. 2014 432 
fesas do goleiro. Assim sendo, nos propusemos neste estudo a descrever e analisar a frequência e a tipologia das ações defensivas que desencadearam contra-ataques nos jogos entre as seleções semifinalistas da VI Copa do Mundo de Futsal, considerando aquelas executadas pelos jogadores de linha e pelo goleiro diante de dois tipos de ataque: o posicional e o contra-ataque.

\section{Método}

Trata-se de um estudo descritivo observacional de delineamento transversal (GAYA, 2008). Foram analisadas $125(31,2 \pm 3,5)$ ações táticotécnicas, retiradas de quatro jogos vídeo gravados entre as seleções semifinalistas da VI Copa do Mundo de Futsal FIFA, respectivamente: Brasil x Rússia (semifinal); Espanha x Itália (semifinal); Rússia x Itália (decisão de $3^{\circ}$ e $4^{\circ}$ lugares); e Brasil x Espanha (final). A seleção da presente amostra foi do tipo não-probabilístico intencional (CASTRO; MESQUITA, 2008), e teve como critério o fato de as equipes pertencerem a um grupo de futsalonistas de elite, participantes de uma competição oficial internacional.

\section{Instrumentos e procedimentos}

A coleta de dados foi feita quando da observação das imagens vídeo gravadas dos jogos em mídia DVD. As cenas foram editadas no software Nero Vision 4 e, posteriormente, analisadas. $\mathrm{O}$ apelo ao meio audiovisual foi escolhido por este permitir a visualização repetida e detalhada dos comportamentos tático-técnicos, de modo a diminuir os erros de observação. Os dados foram anotados em formulários específicos elaborados pelos pesquisadores.

\section{Categorias de análise e qualificação das ações defensivas}

Baseando-nos em Santana e Garcia (2007), estabelecemos duas categorias de análise das ações defensivas que desencadearam os contra-ataques, segundo o agente envolvido e a fase do jogo na qual ele empregou a ação: $\left(1^{a}\right)$ executadas pelos jogadores de linha diante do ataque posicional e do contra-ataque; $\left(2^{\mathrm{a}}\right)$ executadas pelo goleiro diante do ataque posicional e do contra-ataque.

A ação defensiva diante do ataque posicional foi anotada toda vez que os defensores estiveram posicionados em sistema, agrupados atrás da linha da bola. A ação defensiva diante do contra-ataque ocorreu toda vez que os defensores estiveram desequilibrados posicional ou numericamente.

Pensar a Prática, Goiânia, v. 17, n. 2, p. 431-442, jan./mar. 2014 433 
A observação das imagens teve o objetivo inicial de qualificar as ações defensivas empregadas diante dessas duas situações do jogo ofensivo. Isso nos permitiu distinguir nove tipos específicos de comportamentos:

- Interceptação de passe da linha diante do ataque posicional: quando o jogador de linha interceptou a bola passada entre os adversários.

- Desarme da linha diante do ataque posicional: quando o jogador de linha recuperou a bola que estava em posse de um adversário.

- Bloqueio da linha diante do ataque posicional: quando o jogador de linha se posicionou entre o adversário de posse da bola e a sua própria meta, bloqueando um chute ao gol.

- Interceptação de passe da linha diante do contra-ataque: quando o jogador de linha da equipe que sofria o contra-ataque interceptou a bola passada entre os adversários.

- Desarme da linha diante do contra-ataque: quando o jogador de linha da equipe que sofria o contra-ataque recuperou a bola que estava em posse de um adversário.

- Defesa do goleiro diante do ataque posicional: quando o goleiro agarrou a bola finalizada contra a sua meta.

- Rebote do goleiro diante do ataque posicional: quando o goleiro defendeu parcialmente a bola finalizada contra a sua meta.

- Defesa do goleiro diante do contra-ataque: quando o goleiro da equipe que sofria o contra-ataque agarrou a bola finalizada contra a sua meta.

\section{Qualidade da informação}

Com o objetivo de verificar a consistência das observações, foi aplicada a Concordância Entre Observadores (CEO), que estipula uma concordância acima de 0,80, em média, para ser considerado um forte índice (THOMAS, NELSON; SILVERMAN, 2007). Foi realizada uma prova de reprodutibilidade intra-observador, com intervalo de 15 dias, e outra, inter-observador. Diante dos dados coletados, foi analisada a porcentagem de acordos e desacordos. Registraram-se, respectivamente, os valores de 99,2\% e 97,6\% para o agente da ação; $90,5 \%$ e $91,3 \%$ para os tipos de ações defensivas; e $100 \%$ e $96 \%$ para a fase do jogo ofensivo.

\section{Análise estatística}

Foram determinados valores de frequência absoluta $(F)$ e relativa (\%) para os dados obtidos no estudo.

Pensar a Prática, Goiânia, v. 17, n. 2, p. 431-442, jan./mar. 2014 434 


\section{Resultados e discussão}

A Tabela 1 demonstra que, das 125 ações analisadas, 89,6\% foram executadas quando os agentes defenderam em sistema contra o ataque posicional, ou seja, a equipe se encontrava equilibrada e agrupada atrás da linha da bola. Igualmente, verifica-se que a participação defensiva da linha é superior à do goleiro, respectivamente, $90,4 \%$ e 9,6\%.

Tabela 1 - Frequência de ações defensivas que desencadearam contraataques executadas por jogadores de linha e goleiros diante do ataque posicional e do contra-ataque

\begin{tabular}{cccc}
\hline Agente & Fase do jogo & F & $\%$ \\
\hline Linha & Ataque posicional & 104 & 83,2 \\
Linha & Contra-ataque & 9 & 7,2 \\
Goleiro & Ataque posicional & 8 & 6,4 \\
Goleiro & Contra-ataque & 4 & 3,2 \\
\hline & & 125 & 100 \\
\hline
\end{tabular}

A Tabela 2 discrimina os tipos e a frequência das ações defensivas executadas pelos jogadores de linha diante das duas fases do jogo, com destaque para a interceptação de passe e o desarme, que representam $87,6 \%$ das ações.

Tabela 2 - Tipo e frequência das ações defensivas que produziram contra-ataques executadas por jogadores de linha diante do ataque posicional e do contra-ataque

\begin{tabular}{|c|c|c|c|}
\hline Ações defensivas & Fase do jogo & $\mathrm{F}$ & $\%$ \\
\hline Interceptação de passe & Ataque posicional & 52 & 46 \\
\hline Desarme & Ataque posicional & 40 & 35,4 \\
\hline Bloqueio & Ataque posicional & 12 & 10,6 \\
\hline Desarme & Contra-ataque & 5 & 4,4 \\
\hline Interceptação de passe & Contra-ataque & 2 & 1,8 \\
\hline Bloqueio & Contra-ataque & 2 & 1,8 \\
\hline Total & & 113 & 100 \\
\hline
\end{tabular}

Pensar a Prática, Goiânia, v. 17, n. 2, p. 431-442, jan./mar. 2014 435 
A Tabela 3 discrimina os tipos e a frequência das ações defensivas executadas pelos goleiros diante das duas fases do jogo, com vantagem do rebote sobre a defesa.

Tabela 3 - Frequência das ações defensivas que produziram contra-ataques executadas por goleiros diante do ataque posicional e do contraataque

\begin{tabular}{|c|c|c|c|}
\hline Ações defensivas & Fase do jogo & $\mathrm{F}$ & $\%$ \\
\hline Rebote & Ataque posicional & 4 & 33,33 \\
\hline Defesa & Ataque posicional & 4 & 33,33 \\
\hline Rebote & Contra-ataque & 3 & 25 \\
\hline Defesa & Contra-ataque & 1 & 8,33 \\
\hline Total & & 12 & 100 \\
\hline
\end{tabular}

A incidência de ações defensivas maior da linha do que dos goleiros identificada na Tabela 1 pode ser explicada tanto em função de ser maior o número de jogadores de linha, quanto por serem estes os que iniciam a resistência defensiva sobre o adversário. A rigor, o goleiro atua quando a linha é superada. Por outro lado, ressalta-se a participação do goleiro na origem do contra-ataque, uma tendência corroborada pelo estudo de Santana e Garcia (2007).

Ao considerarmos as fases do jogo separadamente, verifica-se maior ocorrência de ações defensivas diante do ataque posicional e menor diante do contra-ataque, respectivamente, $89,6 \%$ e $10,4 \%$.

Igualmente, quando analisadas separadamente as ações defensivas da linha e do goleiro, verifica-se que, em ambos os casos, é maior a frequência daquelas diante do ataque posicional do que do contra-ataque, respectivamente, $92 \%$ e $8 \%$ para a linha e $67 \%$ e $33 \%$ para o goleiro.

No caso da linha, é plausível que essa maior frequência tenha ocorrido em virtude de a defesa, ao se confrontar com o ataque posicional, posicionar-se em sistema, isto é, com os jogadores agrupados atrás da linha da bola, o que tende a facilitar o emprego de ações defensivas e a ajuda mútua (SILVA; CALADO FILHO, 2005). Isso ratifica que o confronto com um ataque sistematizado oportuniza decodificar as intenções dos adversários quando de seu início, otimizando a seleção da melhor tomada de decisão defensiva (PARLEBAS, 1998; PÉREZ; GABILONDO, 2005).

Por outro lado, a menor frequência de ações defensivas da linha diante do contra-ataque pode ter a ver com a fase da defesa que a equipe emprega,

Pensar a Prática, Goiânia, v. 17, n. 2, p. 431-442, jan./mar. 2014 436 
neste caso, de temporização e retorno (LOZANDO et al, 2002). Nessa fase, de modo geral, parte ou um dos defensores se encontra atrás da linha da bola, com a função de retardar a ação ofensiva a fim de que seus companheiros consigam retornar (temporização), e a outra parte está à frente daquela, com a atribuição de correr em direção à própria meta, à máxima velocidade, com o propósito de equilibrar numericamente a defesa (retorno defensivo). Portanto, o desequilíbrio defensivo circunstancial tende a dificultar ações defensivas.

Ao discriminarmos, na Tabela 2, as ações defensivas dos jogadores de linha diante das duas fases do jogo, constata-se que houve maior número de interceptação de passe e desarme do que de bloqueio, respectivamente, $87,61 \%$ e $12,39 \%$. Isso pode ter relação com a maior possibilidade de o jogador desarmar e interceptar passes do que de bloquear, que tende a ser um recurso usado quando não se consegue aplicar as primeiras atitudes. Em parte, esses dados corroboram o achado de Santana e Garcia (2007), que encontraram, respectivamente, a interceptação de passe e o desarme como as ações defensivas principais na origem do contra-ataque de equipes participantes da Liga Futsal.

Se por um lado a interceptação de passe e o desarme são as ações defensivas mais incidentes, seguidas pelo bloqueio, por outro lado, ao se comparar a frequência obtida das ações defensivas da linha diante do ataque posicional (AP) e do contra-ataque (CA), verifica-se uma ordem distinta de incidência. Diante do AP, encontrou-se a interceptação de passe, seguida do desarme e do bloqueio; diante do CA, encontrou-se o desarme seguido da interceptação de passe e do bloqueio. Destaca-se, igualmente, o menor número de bloqueios em ambos os casos, o que pode ter a ver com o fato de os atacantes terem evitado chutes quando tiveram pela frente um defensor, e de optarem pelo passe ou o drible, dando condições para que a defesa interceptasse o passe ou desarmasse.

Ao discriminarmos na Tabela 3 as ações do goleiro diante do ataque posicional e do contra-ataque, constatamos superioridade do rebote diante da defesa, respectivamente, $58 \%$ e $42 \%$. Este se traduz num dado preocupante, pois o rebote do goleiro exigiria a percepção/ação de um jogador de linha para encontrar a bola, a fim de se iniciar o contra-ataque, ao passo que a sua defesa se constitui num indicador promissor quando se pensa na sequência da jogada, na medida em que, com a posse da bola, o goleiro teria condições de iniciar, efetivamente, o contra-ataque. Santana e Garcia (2007) demonstraram que esse jogador, mediante passes e/ou lançamentos, com os pés ou com as mãos, assiste os colegas.

Esse achado chama a atenção tanto para o risco que o ataque posicional corre quando termina sua elaboração chutando a bola nas mãos do golei-

Pensar a Prática, Goiânia, v. 17, n. 2, p. 431-442, jan./mar. 2014 437 
ro adversário, quanto enfatiza a necessidade de os defensores ficarem atentos ao rebote do goleiro, conquistando a posse da bola antes do adversário, a fim de se iniciar o contra-ataque.

\section{Conclusão}

Notou-se que a produção de contra-ataques no jogo de futsal de alto rendimento exige dos jogadores de linha e do goleiro acentuada e específica participação defensiva. Dos primeiros, a interceptação de passe, o desarme e o bloqueio; do segundo, defesas e rebotes.

As ações de interceptar passes e desarmar são centrais para a produção de contra-ataques, sobretudo diante do ataque posicional, quando a equipe agrupa seus jogadores atrás da linha da bola e defende em sistema, mas também diante do contra-ataque.

Os resultados do estudo contribuem para a compreensão da realidade competitiva e para a criação de um conjunto de indicadores para o treino defensivo, com o qual os treinadores poderão simular situações contextualizas, a fim de gerar certas regularidades táticas compatíveis com as exigências do jogo de futsal.

Pode-se apontar como limitação do estudo a ausência da localização territorial das ações defensivas empregadas pelos jogadores de linha e pelo goleiro. O seu conhecimento retrataria mais sobre o comportamento defensivo das equipes semifinalistas na recuperação da bola contra o ataque posicional e o contra-ataque.

\section{Aplicações práticas}

Apoiados nos achados deste estudo, sugerimos um conjunto de indicadores técnico-táticos defensivos relevantes para o treino de futsal:

- Em função da interdependência entre os momentos do jogo, isto é, entre a defesa e o jogo de transição ofensiva, sugere-se que o treino contemple situações contextualizadas nas quais os jogadores tenham de marcar agrupados atrás da linha da bola (em sistema) e em desequilíbrio (defesa de transição) e, no caso de interceptar, desarmar ou bloquear, encadear contra-ataques.

- Em virtude da participação do goleiro ao defender/agarrar chutes e também ao rebatê-los, sugere-se que o treino simule situações semelhantes, a fim de aprimorar a reposição da bola no contra-ataque após uma defesa e a conquista da posse de bola pelos jogadores de linha após o seu rebote.

Pensar a Prática, Goiânia, v. 17, n. 2, p. 431-442, jan./mar. 2014 
- Ao se constatar a ausência de interceptações de passe do goleiro, sugere-se que o treino simule situações nas quais esse jogador tenha de realizar coberturas interceptando passes, de modo a encadear possíveis contra-ataques.

\title{
GAME ANALYSIS ON FUTSAL: COUNTERATTACK AND DEFENSIVE ACTIONS
}

\begin{abstract}
This study was designed to describe and analyze the frequency and types of defensive actions that triggered counterattacks in futsal games. The indicators have been raised considering the actions employed by line players and by the goalkeeper before the positional attack and counterattack. Used descriptive observational method and has been reviewed $125(31,75 \pm 2,98)$ actions, taken from four matches between the semifinalists of the Futsal World Cup VI. It was noted that the production of counterattacks, especially before the happened attack positional and demanded the line players trap, disarm and lock passes; goalkeepers already participated with defenses and rebounds. The study contributes to the creation of a set of indicators for the defensive training with which coaches could simulate contextualized situations in order to generate certain regularities tactics consistent with the requirements of the sport.
\end{abstract}

Keywords: Futsal. Analysis. Game. Defence.

\section{ANÁLISIS DEL JUEGO DE FUTSAL: ACCIONES DEFENSIVAS Y CONTRAATAQUES}

\section{Resumen}

Este artículo pretende describir y analizar la frecuencia y tipos de acciones defensivas que desencadenó contraataques (CA) en juegos de fútbol sala. Fueran levantadas las acciones empleadas por jugadores y por lo portero ante el ataque posicional y CA. Fueram examinadas $125(31.75 \pm 2,98)$ acciones, procedentes de cuatro partidos entre las semifinalistas de la VI Copa del Mundo de Fútbol Sala. Se observó que la producción de CA sucedió, sobre todo, en el ataque posicional y exigió del jugadores que el intercepto de la línea pasa, desarmar y cerradura; los porteros participaron con defensa y rebotes. El estudio contribuye a la creación de un conjunto de indicadores para la formación defensiva con la que los entrenadores pueden simular situaciones de contextualizas para generar ciertas tácticas de regularidades consistentes con los requisitos del deporte.

Palabras-claves: Futsal. Análisis. Juego. Defensa.

\section{Referências}

Pensar a Prática, Goiânia, v. 17, n. 2, p. 431-442, jan./mar. 2014 439 
AMARAL, R.; GARGANTA, J. A modelação do jogo em futsal. Análise sequencial do $1 \mathrm{x} 1$ no processo defensivo. Revista Portuguesa de Ciências de Desporto, Porto, v.5, n.3, p.298-310, 2005. Disponível em: <http://www.fade.up.pt/rpcd/_arquivo/artigos_soltos/vol.5_nr.3/1.05.r_amar al.pdf\}>. Acesso em: 3 maio 2012.

ANDRADE JUNIOR, J. Futsal: aquisição, iniciação e especialização. Curitiba: Juruá, 2007.

BONVICINI, J. Baloncesto de transición. In: MURREY, B. (Ed.). Entrenar el contraataque. Barcelona: Paidotribo, p.19-27, 2004.

CASTRO, J.M.; MESQUITA, I. Estudo das implicações do espaço ofensivo nas características do ataque no voleibol masculino de elite. Revista Portuguesa de Ciências do Desporto, Porto, v.8, n.1, p.114-125, 2008. Disponível em:

$\langle$ http://www.fade.up.pt/rpcd/_arquivo/artigos_soltos/vol.8_nr.1/1.11.pdf $>$. Acesso em: 5 maio 2012.

CHAVES CHAVES, J.L.; RAMÍREZ AMOR, J.A. Táctica y estratégia em fútbol sala: situaciones de ataque y defensa. Barcelona: Hispano Europea, 1998.

DUARTE, R. Análise da utilização da posse de bola durante o processo ofensivo no futsal. Revista Motricidade, Vila Real, Portugal, vol.4, n.2, p. 77-83, 2008.2 Disponível em: <http://revistas.rcaap.pt/motricidade/article/view/514/458>. Acesso em: 3 maio 2012.

FUKUDA, J.P.; SANTANA, W.C. Análise dos gols em jogos da Liga Futsal 2011. Revista Brasileira de Futsal e Futebol, São Paulo, v.4, n.11, p.6266, 2012. Disponível em <http://www.rbff.com.br/index.php/rbff/article/view/125/124>. Acesso em: 5 maio 2013.

GARGANTA, J. O treino da táctica e da estratégia nos jogos desportivos. In: GARGANTA, J. (Ed.). Horizontes e órbitas no treino dos jogos desportivos. Porto: (pp.51-61). Porto: FCDEFUP, p. 51-61, 2000.

GARGANTA, J. Modelação táctica em jogos desportivos: a desejável cumplicidade entre pesquisa, treino e competição. In: TAVARES, F; GRAÇA, A; 
GARGANTA, J; MESQUITA, I. (Eds.). Olhares e contextos da performance nos jogos desportivos. Porto: (pp.108-121). Porto: FCDEFUP, p. 108-121, 2008.

GAYA, A. Desenhos metodológicos V: delineamentos do tipo ex post facto. In: GAYA, A. (Ed.). Ciências do movimento humano: introdução à metodologia da pesquisa. Porto Alegre: Artmed, p. 151-172, 2008.

JABIR, J. El ataque de transición. In: MURREY, B. (Ed.). Entrenar el contraataque. Barcelona: Paidotribo, p.39-48, 2004.

LOZANO, J. et al. Táctica en alta competición. Madrid: Federación Madrileña de Futbol-Sala, 2002.

MARCHI, R. et al. Incidência de gols resultantes contra-ataques de equipes de futsal. Conexões, Campinas, v.8, n.3, p. 16-22, 2010. Disponível em: $\langle$ http://fefnet178.fef.unicamp.br/ojs/index.php/fef/article/view/513 >. Acesso em: 28 abr. 2012.

PARLEBAS, P. Juegos, deportes y sociedades: léxico de praxiología motriz. Barcelona: Paidotribo, 1998.

PÉREZ, L.; GABILONDO, J. El proceso de toma de decisiones en el deporte: clave de la eficiência y el rendimiento óptimo. Barcelona: Paidós, 2005.

SAMPEDRO, J. Fundamentos de táctica deportiva: análisis de la estratégia de los deportes. Madrid: Gymnos, 1999.

SANTANA, W. Futsal: apontamentos pedagógicos na iniciação e na especialização. Campinas: Autores Associados, 2004.

SANTANA, W.C. A visão estratégico-tática de técnicos campeões da Liga Nacional de Futsal. 2008. 260f. Tese (Doutorado em Educação Física) - Universidade Estadual de Campinas, Brasil, 2008.

SANTANA, W.C.; GARCIA, O.B. A incidência do contra-ataque em jogos de futsal de alto rendimento. Revista Pensar a Prática, Goiânia, v.10, n.1, p.153-162, 2007.2 Disponível em: $<$ http://www.revistas.ufg.br/index.php/fef/article/viewArticle/142>. Acesso em: 7 maio 2012.

Pensar a Prática, Goiânia, v. 17, n. 2, p. 431-442, jan./mar. 2014 441 
SILVA, M. et al. Ações ofensivas no futsal: uma comparação entre as situações de jogo organizado, de contra-ataque e de bola parada. Revista Portuguesa de Ciências do Desporto, Porto, v.4, n.2, p.199, 2004. Disponível em:

〈http://www.fade.up.pt/rpcd/_arquivo/artigos_soltos/vol.4_nr.2/06.pdf>. Acesso em: 7 maio 2012.

SILVA, R.; CALADO FILHO, C. Formación de entrenadores de futsal de máximo nível: técnica y táctica. Espanha: Fédération Internationale de Football Association, 2005.

THOMAS, J.R.; NELSON, JK.; SILVERMAN, S.J. Métodos de pesquisa em atividade física. 5. Ed. Porto Alegre: Artmed, 2007.

VELASCO, J.; LORENTE, J. Entrenamiento de base em fútbol sala: fundamentos teóricos e aplicaciones prácticas. Barcelona: Paidotribo, 2003.

Recebido em: 18/06/2013

Revisado em: 05/08/2013

Aprovado em: 26/11/2013

Endereço para correspondência:

wilton@pedagogiadofutsal.com.br

Wilton Carlos de Santana

Universidade Estadual de Londrina, Centro de Educação Física e Desportos.

Rodovia Celso Garca Cid, km 380

Campus Universitário

86055-900 - Londrina, PR - Brasil

Pensar a Prática, Goiânia, v. 17, n. 2, p. 431-442, jan./mar. 2014 